\title{
FORMAÇÃO DE PROFESSORES NO BRASIL: 10 ANOS DE EMBATE ENTRE PROJETOS DE FORMAÇÃO
}

\author{
Helena Costa Lopes de Freitas
}

\begin{abstract}
RESUMO: O trabalho analisa as políticas de formação de professores centrando-se na análise das Diretrizes Nacionais para Formação Inicial de Professores para a Educação Básica em Nível Superior, por identificar nesse documento legal a materialização das múltiplas facetas das políticas de formação, desde a definição das competências e habilidades, passando pela avaliação de desempenho e organização curricular. Identifica-se a temática da avaliação como estreitamente vinculada à questão da formação de professores, principalmente em virtude das políticas para a formação de professores e da adoção do modelo de competências na definição das Diretrizes Nacionais para Formação Inicial de Professores para a Educação Básica em Nível Superior. A criação de um sistema federativo de certificação de competências dos professores indica que estamos vivenciando o processo de flexibilização do trabalho docente comprometendo a luta histórica dos educadores pela profissionalização do magistério.
\end{abstract}

Palavras-chave: Profissionalização do educador. Diretrizes. Políticas de formação.

\section{Teacher Training in BraziL: \\ 10 Years of Struggle Among Training Projects}

ABSTRACT: This paper analyses the policies of teacher training focalizing on the Directives on Teachers' Initial Training for Basic Education in Higher Education. This legal document can be seen as the materialization of the multiple facets of the training policies, from the definition of competence and skills to the assessment of performance and curricular organization. The theme of assessment is assumed as closely linked to the issue of teacher training mainly because of the policies of teacher training and the adoption of the model of competence in the definition of the Brazilian Directives on Teachers' Initial Training

Professora da Faculdade de Educação da Universidade Estadual de Campinas (UNICAmP).

E-mail: helena.freitas@uol.com.br 
for Basic Education in Higher Education. The creation of a federative system of teacher competence certification indicates that we are experiencing the process of flexibilization of teacher work, which jeopardizes the historical fight of educators for the professionalization of teacher training.

Key words: Professionalization of educators. Directives. Training policies.

\section{Introdução}

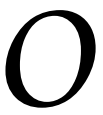

debate sobre políticas de formação de professores evoca dois movimentos que se entrelaçam de forma contraditória na realidade atual: o movimento dos educadores e sua trajetória em prol da reformulação dos cursos de formação dos profissionais da educação e o processo de definição das políticas públicas no campo da educação, em particular da formação de professores, que tem nos Referenciais Curriculares para Formação de Professores (1999), no Parecer $n^{\circ} 115 / 99$ que criou os institutos superiores de educação e nas Diretrizes Curriculares para a Formação Inicial de Professores para a Educação Básica em Nível Superior (2001), sua expressão material mais visível. Estes documentos fazem parte de um conjunto de orientaçôes oficiais sobre ajustes curriculares nos diferentes cursos de formação profissional que se desenvolvem desde final de 1997, quando o CNE (Resolução CP no 04/97) aprovou as orientações gerais para a construção de novas diretrizes curriculares para os cursos de graduação. Evidenciam, portanto, o processo de flexibilização curricular em curso tendo em vista a adequação do ensino superior às novas demandas oriundas do processo de reestruturação produtiva por que passam os diferentes países, objetivando adequar os currículos aos novos perfis profissionais resultantes dessas modificaçôes. Catani alerta para os riscos deste ideário da flexibilização curricular, afirmando que tais "dinamicas certamente 'naturalizam' o espaço universitário como campo de formaçāo profissional em detrimento de processos mais amplos reduzindo, sobretudo, o papel das universidades" (Catani et al., 2000).

\section{I - Situando historicamente a formação do educador}

As idéias que discuto neste artigo têm suas raízes fincadas na trajetória do movimento dos educadores em luta pela sua formação 
e pela profissionalização do magistério, representada pela ANFOPE Associação Nacional pela Formação dos Profissionais da Educação. Os caminhos trilhados e a vivência coletiva da experiência singular nos últimos anos tornam parte das idéias traçadas aqui, minha interpretação particular, a qual socializo com o propósito de aprofundar o debate com os parceiros nesta caminhada.

Para traçar uma visão panorâmica da formação de professores em nosso país, tomo como ponto de partida as análises que vêm sendo feita pelos educadores (Freitas, L.C., 2000; Freitas, H., 1999; Kuenzer, 1998; Valle, 1999, 2000; entre outros) e por suas entidades organizativas - ANFOPE, FORUMDIR, ANPED, ANPAE, CEDES, Fórum Nacional em Defesa da Formação de Professores, CNTE, entre outras - no sentido de identificar os (des)caminhos das políticas de formação de professores nos últimos dez anos, buscando nesta história identificar os elementos de superação das condições atuais em que se encontra a educação e em particular a formação de professores, campos assolados pelas determinações dos organismos internacionais que impóem aos diferentes países seus fins e objetivos, tornando-os subordinados às orientaçōes políticas neoliberais e mais bem adequados às transformaçóes no campo da reestruturação produtiva em curso.

Faço esta recuperação de um lugar determinado, no campo da luta política e da luta de idéias, por assim entender o quadro atual em que nos movimentamos, os educadores, em uma realidade em que a "perda de referências" e as "incertezas" da pós-modernidade passaram a ser um atributo de qualidade das mentes abertas a toda sorte de "novas" idéias e "novas" referências que vêm tentando "desconstruir" (felizmente até o momento sem sucesso) a própria história do movimento dos educadores em luta pela sua formação e profissionalização.

A luta dos educadores a partir do final dos anos 70 e início da década de 1980, no quadro do movimento mais geral da democratização da sociedade, trouxe contribuições importantes para a educação e para a forma de olhar a escola e o trabalho pedagógico, ao colocar em evidência as relações de determinação existentes entre educação e sociedade e a estreita vinculação entre a forma de organização da sociedade, os objetivos da educação e a forma como a escola se organiza. No âmbito da formação do educador, o Comitê Nacional, a CONARCFE - Comissão Nacional pela Reformulação dos Cursos de Formação do Educador - e posteriormente e até os dias de hoje a ANFOPE, têm papel fundamental no redirecionamento das discussões 
travadas no âmbito oficial que entendia a formação de professores como uma questão de formação de recursos humanos para a educação dentro da ótica tecnicista que imperava no pensamento oficial.

Os anos 80 representaram a ruptura com o pensamento tecnicista que predominava na área até então. No âmbito do movimento da formação, os educadores produziram e evidenciaram concepçôes avançadas sobre formação do educador, destacando o caráter sócio-histórico dessa formação, a necessidade de um profissional de caráter amplo, com pleno domínio e compreensão da realidade de seu tempo, com desenvolvimento da consciência crítica que lhe permita interferir e transformar as condições da escola, da educação e da sociedade. Com esta concepção emancipadora de educação e formação, avançou no sentido de buscar superar as dicotomias entre professores e especialistas, pedagogia e licenciaturas, especialistas e generalistas, pois a escola avançava para a democratização das relações de poder em seu interior e para a construção de novos projetos coletivos. Como parte importante desta construção teórica a partir das transformaçôes concretas no campo da escola, construiu a concepção de profissional de educação que tem na docência e no trabalho pedagógico a sua particularidade e especificidade.

Os educadores vêm construindo teórica e praticamente a concepção de base comum nacional, entendendo-a como instrumento de luta contra a degradação da profissão (ANFOPE, 1992), e que hoje se manifesta como poderoso referencial para garantir a igualdade de condições de formação em oposição à concepção de igualdade de oportunidades originária da nova concepção de eqüidade tão enfatizada no novo glossário da pós-modernidade e nas políticas públicas atuais.

Os princípios gerais do movimento manifestavam, em sua construção, a compreensão dos educadores sobre a necessidade de vincular a concepção da forma de organização da escola à formação do educador, vinculando-a, por sua vez, às grandes questôes sociais e ao movimento dos trabalhadores pela construção de uma nova sociedade, justa, democrática e igualitária. Entendia-se - e entendese - a luta pela formação do educador, portanto, inserida na crise educacional brasileira, parte de uma problemática mais ampla, expressão das condições econômicas, políticas e sociais de uma sociedade marcada pelas relações capitalistas de produção e, portanto, profundamente desigual, excludente e injusta, que coloca a maioria da população em uma situação de desemprego, exploração e miséria. Pensar a escola e sua forma de organização supõe, em contrapartida 
e ao mesmo tempo, colocar-se questôes que ultrapassam (e podem até negar) a concepção reducionista de educação como formação para a cidadania, elevando nosso pensamento para as interrogações dos fins da educação, os quais, ao final, desvelam projetos históricos diferenciados e antagônicos: Que futuro queremos para o nosso povo? E como este futuro se constrói a partir do presente? Os educadores compartilharam sempre da idéia de que "ter presente estas amarras mais amplas é fundamental para evitar que o debate sobre formação do educador se concentre apenas em questôes técnicas, etapa já vencida há décadas pelo movimento" (ANFOPE, 1989), mas que retornam com força nas políticas atuais.

Outras duas questões ainda orientavam os debates gerais: no movimento de luta pela democratização da sociedade brasileira está inserida a necessidade da gestão democrática da escola e da educação em todos os níveis e a explicitação da luta pela autonomia universitária, que no entendimento dos educadores passa pela descentralização do poder de decisão na área da educação, tanto em nível interno quanto externo (gestão democrática), autonomia que não implica, tal como se manifesta a visão atual do Estado brasileiro, a progressiva retirada de recursos públicos e o conseqüente descomprometimento do Estado com a manutenção e o desenvolvimento das instituiçôes públicas de ensino.

No contexto dessas discussões, as reformulações curriculares, particularmente no âmbito da formação de professores de educação infantil e séries iniciais do ensino fundamental, no interior dos cursos de pedagogia, cresceram e prosperaram com base nas concepções mais progressistas e avançadas. Aos novos desafios colocados para elevar a formação de professores de educação infantil e séries iniciais do ensino fundamental em nível superior, novas respostas foram sendo construídas pelas IEs e pelas faculdades/ departamentos/centros de educação, criando um fértil debate que se prolonga até os dias de hoje, em que pese todas as tentativas de definições e amarras legais ${ }^{1}$ atuais no sentido de desfigurar o curso de pedagogia como um curso de formação de professores profissionais da educação.

No campo da formação de professores para as séries finais do ensino fundamental e para o ensino médio, em que pese a dependência, de grande parte dessa formação, das investigações, pesquisas e dos estudos pedagógicos que se desenvolvem nas faculdades de educação e em seus programas de pós-graduação, as modificações 
curriculares e o movimento das instituiçôes universitárias não acompanhou, com a mesma intensidade, e no mesmo tempo, os debates e as reformulações desenvolvidos nos cursos de pedagogia das diferentes IES. As razões desta situação contraditória estão minuciosamente relatadas em inúmeros estudos e pesquisas (Candau \& Lüdke, 1988; Lüdke, 1994) desenvolvidos por colegas da área e ainda nos documentos finais de todos os Encontros Nacionais da CONARCFE e da ANFOPE, desde 1980.

Há que ressaltar, no entanto, a intensa atividade dos Fóruns de Licenciaturas, espaços de discussão permanentes que se desenvolvem em inúmeras universidades, particularmente as públicas federais, que vêm investindo, desde o início da década de 1990, na criação e institucionalização desses espaços, contribuindo para aprofundar as discussões sobre formação de professores, principalmente na busca de superação do trágico "modelo" 3+1 (ANFOpe, 2000; Marques \& Pereira, 2002).

A produção de propostas alternativas, que buscam exercer a ruptura com esse modelo dos cursos de formação, tem sido uma constante no interior de várias IES, na organização dos Fóruns de Licenciaturas e de inúmeras experiências que se orientam pelos princípios da base comum nacional construída pelo movimento e pela ANFOPE.

Mas, se a década de 1980 representou, para os educadores, o marco da reação ao pensamento tecnicista das décadas de 1960 e 1970, os anos 90, contraditoriamente, foram marcados também pela centralidade no conteúdo da escola (habilidades e competências escolares), fazendo com que fossem perdidas dimensóes importantes que estiveram presentes no debate dos anos 80. A ênfase excessiva do que acontece na sala de aula, em detrimento da escola como um todo (Freitas, 2000), o abandono da categoria trabalho ${ }^{2}$ pelas categorias da prática, prática reflexiva, nos estudos teóricos de análise do processo de trabalho, naquele momento histórico da abertura política e da democratização da escola, recuperavam a construção dos sujeitos históricos professores como sujeitos de suas práticas. No entanto, a ênfase no caráter da escola como instituição quase que exclusivamente voltada para a socialização dos conhecimentos histórica e socialmente construídos terminou por centrar a ação educativa na figura do professor e da sala de aula, na presente forma histórica que ela tem, tornando-se alvo fácil das políticas neoliberais baseadas na qualidade (da instrução, do conteúdo), em detrimento da formação humana multilateral (Freitas, 2000). 


\section{Anos 90: os embates entre concepções de educação e formação}

No contexto desses embates teóricos, entramos nos anos 90, denominados de "Década da Educação", que representaram o aprofundamento das políticas neoliberais em resposta aos problemas colocados pela crise do desenvolvimento do capitalismo desde os anos 70 , na qual a escola teve papel importante. A educação e a formação de professores ganham, nessa década, importância estratégica para a realização das reformas educativas (Freitas, 1999), particularmente a partir de 1995, quando tem início o Governo Fernando Henrique Cardoso. Em 7 de fevereiro de 1995, um mês após assumir a presidência, Fernando Henrique divulga os "5 pontos" de seu governo para a melhoria do ensino público: a distribuição das verbas federais diretamente para as escolas, sem passar pelos estados e municípios; criação do Sistema Nacional de Educação a Distância, com a instalação de aparelhos de TV em cada escola, com o objetivo de "preparar os professores para que eles possam ensinar melhor"; a melhoria da qualidade dos 58 milhóes de livros didáticos distribuídos anualmente para as escolas; a reforma do currículo para melhorar o conteúdo do ensino, com o estabelecimento de matérias obrigatórias em todo o território nacional; e a avaliação das escolas por meio de testes, premiando aquelas com melhor desempenho.

Educação para Todos, Plano Decenal, Parâmetros Curriculares Nacionais, diretrizes curriculares nacionais para a educação básica, para a educação superior, para educação infantil, educação de jovens e adultos, educação profissional e tecnológica, avaliação do SAEB Sistema Nacional de Avaliação da Educação Básica -, Exame Nacional de Cursos (Provão), ENEm - Exame Nacional do Ensino Médio-, descentralização, FUNDEF - Fundo de Manutenção e Desenvolvimento do Ensino Fundamental e de Valorização do Magistério -, Lei da Autonomia Universitária, novos parâmetros para as IES, são medidas que objetivam adequar o Brasil à nova ordem, bases para a reforma educativa que tem na avaliação a chave-mestra que abre caminho para todas as políticas: de formação, de financiamento, de descentralização e gestão de recursos.

No desenvolvimento e na implementação das políticas educacionais neoliberais, a qualidade da educação, assumida como bandeira pelos diferentes setores governamentais e empresariais, adquire importância estratégica, como condição para o aprimoramento do processo de acumulação de riquezas e aprofundamento do capitalismo. 
A concepção tecnicista de educação que alcançou grande vigor no pensamento educacional da década de 1970, criticada e rebatida na década de 1980, retorna sob nova roupagem, no quadro das reformas educativas em curso, anunciando que "a globalização econômica confronta o Brasil com os problemas da competitividade para a qual a existência de recursos humanos qualificados é condição indispensável" (Mello, 1999, p. 2, grifo nosso).

As referências e as bases para as políticas de formação de professores vinculam-se estreitamente às exigências postas pela reforma educativa da educação básica, para a formação das novas gerações. A formação inicial de professores, na ótica oficial, "deve ter como primeiro referencial as normas legais e recomendações pedagógicas da educação básica" (Mello, 1999, p. 10).

Em conseqüência, as políticas de formação de professores pressupõem o encaminhamento das soluções no âmbito restrito da política de educação básica, independentemente da problemática do ensino superior como tal. Em artigo anterior (Freitas, 1999), evocamos documento de Mello (1999) que afirmava ser

inviável para o poder público financiar a preços das universidades 'nobres' a formação de seus professores de educação básica que se contam em mais de milhão. Com um volume de recursos muito menor, um sistema misto de custo baixos, tanto públicos quanto privados, configura um ponto estratégico de intervenção para promover melhorias sustentáveis a longo prazo na escolaridade básica. (Grifos nossos)

Importante destacar que esta recomendação, fielmente cumprida em nosso país, faz parte das recomendaçóes presentes no documento do Banco Mundial, de 1995, intitulado "La enseñanza superior: las leciones derivadas de la experiência”.

A política de expansão dos institutos superiores de educação e cursos normais superiores, desde 1999, obedece portanto a balizadores postos pela política educacional em nosso país em cumprimento às lições dos organismos financiadores internacionais. Caracterizados como instituiçôes de caráter técnico-profissionalizante, os ISEs têm como objetivo principal a formação de professores com ênfase no caráter técnico instrumental, com competências determinadas para solucionar problemas da prática cotidiana, em síntese, um "prático" (Freitas, 1992).

Os fundamentos e objetivos da criação e expansão destes novos espaços de formação já foram amplamente analisados (Freitas, 1999; 
Aguiar, 1999; entre outros) como parte intrínseca da estratégia da $2^{a}$ etapa da reforma educacional em nosso país: a reforma no campo da formação de professores. A $2^{a}$ etapa da reforma educativa desenvolve-se de forma mais intensa a partir de 1999 e tem como objetivos centrais: 1) dar forma e conteúdo à proposta dos institutos superiores de educação aprovada pelo CNE em setembro de 1999 (Parecer CNE/ CES no 115/99) e, como conseqüência, 2) retirar das faculdades de educação, e em seu interior, do curso de pedagogia, a formação de professores para as séries iniciais do ensino fundamental e da educação infantil. O Decreto no 3.276/99, de dezembro de 99, embora posteriormente modificado, cumpriu esse objetivo com muita eficiência até a Deliberação CNE/CP no 133/2001, à qual nos referiremos posteriormente.

Com efeito, desde 1998 cresce em nosso país o número de IES, aumentando significativamente o número de cursos nas áreas com maior demanda. A área da educação - cursos de pedagogia e algumas licenciaturas (letras e matemática) - é a área de maior crescimento, perdendo apenas para os cursos de administração. Mesmo com toda a polêmica que envolve há décadas o curso de pedagogia e as divergências em relação ao profissional a ser formado nesse espaço, é grande a demanda pela criação de novos cursos e somente no ano de 2000 foram autorizados 142 novos cursos de pedagogia nos diferentes estados. Apesar de todos os esforços das comissôes de especialistas no sentido de garantir a qualidade dos cursos a serem autorizados, nestes últimos quatro anos do Governo Fernando Henrique observa-se a expansão desordenada e, portanto, com qualidade comprometida, de cursos e instituições de ensino superior para formação de professores. Criados como instituições de caráter técnico-profissionalizante, de baixo custo, a expansão exponencial desses novos espaços de formação objetiva, com raras exceçôes, responder às demandas de grande parcela da juventude atual por educação em nível superior, oferecendo-lhes uma qualificação mais ágil, flexível, adequada aos princípios da produtividade e eficiência e com adequação às demandas do mercado competitivo e globalizado. Em uma conjuntura de desvalorização da profissão do magistério, caracterizada pela degradação das condições de funcionamento das escolas, pelas péssimas condições atuais de trabalho, salário e carreira (CNTE, 2001), as novas instituições criadas têm encontrado dificuldades na manutenção de seus cursos de formação de professores exclusivamente como curso normal superior. Vários projetos pedagógicos de cursos de pedagogia em IES isoladas 
têm incorporado outras habilitaçóes no interior desses cursos de pedagogia, tais como tecnologia educacional, pedagogia empresarial, multimídias, entre outras, fato que pode levar a uma fragmentação ainda maior desses cursos, possibilitando uma formação cada vez mais especializada, a qual, inclusive, vem sendo mais bem desenvolvida em outros cursos - como administração, psicologia e recursos humanos, comunicação e informática -, apenas para dar alguns exemplos.

A aprovação da Resolução CNE/CP no 133, em janeiro de 2001, sob a alegação de fazer cumprir as determinações do Decreto $n^{\circ} 3.276 /$ 99 e do Decreto no 3.550/2000 (que alterou o termo "exclusivamente" para "preferencialmente"), abriu mais um capítulo na discussão sobre o curso de pedagogia e as instâncias e o locus de formação dos professores para a educação básica, ao estabelecer definitivamente as regras para os pedidos de autorização de cursos de formação de professores: a formação de professores somente poderá acontecer em universidades e centros universitários (muito mais por conta das prerrogativas da autonomia do que por consentimento do MEC), e nos institutos superiores de educação, criados especificamente para esse fim. Com isso, inúmeros cursos de pedagogia em faculdades isoladas e integradas, que formavam professores, tiveram que se transformar em curso normal superior, ou permanecer como curso de pedagogia, formando exclusivamente o bacharel - especialista para atuar nas tarefas de gestão, supervisão e orientação na instituição escolar.

Confirma-se, assim, o objetivo central desta política, denunciado pela área desde a promulgação da LDB, que é o de retirar das faculdades/ centros de educação nas universidades a responsabilidade pela formação de professores, educadores para atuar em todas as esferas da educação básica. Pelo seu papel histórico na produção do conhecimento crítico da educação, nas atuais determinaçôes legais as faculdades de educação têm sido alijadas intencionalmente de todas as políticas relativas à formação de professores - inicial e continuada. A confirmar-se esta intenção por novas determinaçôes legais, aos cursos de pedagogia caberia exclusivamente a formação do bacharel, caracterizando o retorno à fragmentação das habilitações e a separação da formação de professores da formação dos demais profissionais da educação.

Os mentores intelectuais destas concepções, no campo da educação e da pedagogia, acabam fortalecendo tanto o MEC quanto o CNE na implementação das novas concepções do perfil necessário de professores e especialistas na realidade atual da reforma educativa. Com isso, tentam introduzir novamente no campo da escola, sob o 
manto do pesquisador e cientista da educação, as antigas tarefas do "especialista" supervisor e gestor, agora sobre novas bases, determinadas pelas políticas da reforma educativa que deve "ancorar-se" obrigatoriamente em cada sala de aula.

Ao afirmarem a existência de diferenças qualitativas entre as duas formaçôes - a de pedagogo e a de professor - os autores reduzem os saberes e as especificidades do profissional docente a tarefas menos nobres que aquelas destinadas aos que dominam a ciência pedagógica e a ciência da educação, os pedagogos (Franco, 2002). As especificidades da pedagogia defendidas por esses autores deveriam, na ótica do movimento dos educadores, ser ampliadas como componentes da formação de todos os professores. Somente a política de desqualificação da formação, de degradação e desmantelamento das instituiçôes públicas universitárias e de expansão desqualificada do ensino superior, aliada aos baixos salários, à desvalorização do magistério e às péssimas condições de trabalho dos professores, constitui-se em impeditivo para que a formação de todos os professores alcance os níveis de qualidade superior defendidos por esses setores para desenvolver-se exclusivamente em cursos de bacharelado de pedagogia.

Com isso, estão criadas as condições teóricas e práticas para o surgimento dos novos "capatazes da educação" (Freitas, 1999), aqueles que, formados sobre bases teóricas mais sólidas no campo específico da teoria pedagógica, tornam-se aptos para orientar os pobres "professores tarefeiros", que por suas condições materiais de existência se defrontam com a impossibilidade de se superarem em sua formação teórica. Aqueles terão condições de compreender, organizar, supervisionar e avaliar (principalmente avaliar) o processo pedagógico e o trabalho destes docentes nas instituições escolares. Formados em espaços distintos, sob condiçôes desiguais, submetidos a desafios teóricos de qualidade diferenciada, divididos no trabalho pedagógico da formação de nossas crianças, jovens e adultos, mas... compartilhando o mesmo espaço educativo, resta-nos indagar: Que projeto de escola se concebe a partir desta divisão do trabalho?

Infelizmente, este movimento no campo da formação na graduação vem se firmando, mais recentemente, também na pósgraduação, com a retirada dos programas e das áreas de concentração em ensino de ciências, do Comitê de Educação da CAPES, localizandoos no comitê ou subcomitê na(s) área(s) específica(s) de ensino de ciências (mas abrindo espaço para outras áreas), abrindo as portas para 
os mestrados profissionais na área da formação de professores separados dos mestrados acadêmicos da área da educação.

Nossa hipótese é a de que as atuais políticas para graduação e também para a pós-graduação pretendem gradativamente retirar a formação de professores da formação científica e acadêmica própria do campo da educação, localizando-a em um novo "campo" de conhecimento: da "epistemologia da prática", no campo das práticas educativas ou da práxis. Vários estudos vêm firmando esta perspectiva, fortalecidos pelas reformas educativas das últimas décadas, em particular aqueles que se ancoram, em nosso país, nas contribuições de Nóvoa, Schön, Zeichner, Gaultier, Tardiff e Perrenoud, entre outros.

Whitty (1999), ao analisar as reformas educativas na Inglaterra e no País de Gales, aponta que muitos analistas das reformas têm levantado a hipótese de que a degradação do envolvimento da universidade na formação de professores representa uma tentativa de desmantelar as defesas tradicionais do ensino como profissão. Esta afirmação se refere ao movimento observado em alguns desses países, de deslocar o treinamento dos professores para as escolas (a exemplo dos Parâmetros em Ação, da Rede de Formadores, em nosso país), correndo o risco de limitar o âmbito no qual os alunos desenvolvem perspectivas mais amplas e criticas sobre a educação e igualmente de incentivarem-se formas restritas, ao invés de ampliadas, do exercicio profissional (Adams \& Tulasiewicz, apud Whitty, 1999). Este alerta vem reforçar as análises que têm sido feitas por estudiosos em nosso país, no sentido de apontar os riscos da retirada da formação de professores da ambiência universitária, negando ao professor a sua identidade como cientista e pesquisador da educação, atributos reservados apenas àqueles que atuam no ensino superior (Kuenzer, 1999). Na realidade, sob o discurso da valorização do magistério e sua profissionalização, têm aprofundado a desqualificação e a desvalorização deste profissional. Ao privilegiar a expansão de novas instituições e novos cursos principalmente no setor privado ${ }^{3}$ em vez de investimento massivo no aprimoramento das atuais licenciaturas nas universidades públicas, as políticas atuais do MEC acabaram por colocar nas mãos da iniciativa privada a grande demanda oriunda da dívida histórica do Estado para com a formação em nível superior dos quadros do magistério.

No âmbito da formação continuada, as políticas atuais têm reforçado a concepção pragmatista e conteudista da formação de professores. Neste particular, cabe destacar a redução da concepção 
de formação contínua a programas como os Parâmetros em Ação e a Rede de Formadores, sob patrocínio do MEC em articulação com municípios e algumas instituições formadoras, ${ }^{4}$ e os programas de formação inicial a distância, utilizando-se de mídias interativas e novas tecnologias. Pressionados pelo art. 87, $\$ 4^{\circ}$ da LDB $\mathrm{n}^{\circ} 9.394 /$ 96 que estabelece que "Até o fim da Década da Educação somente serão admitidos professores habilitados em nível superior ou formados por treinamento em serviço", os professores têm sido levados a freqüentar cursos de qualidade duvidosa em grande parte pagos por eles. Em vários estados tais cursos são, em geral, uma demanda das prefeituras que os terceirizam ou "contratam" as IES - públicas ou privadas -, as quais realizam processo seletivo especial de modo que possam atender a esta demanda específica.

Todo esse processo tem se configurado como um precário processo de certificação e/ou diplomação e não qualificação e formação docente para o aprimoramento das condições do exercício profissional. A formação em serviço da imensa maioria dos professores passa a ser vista como lucrativo negócio nas mãos do setor privado e não como política pública de responsabilidade do Estado e dos poderes públicos. O "aligeiramento" da formação inicial dos professores em exercício começa a ser operacionalizado, na medida em que tal formação passa a ser autorizada fora dos cursos de licenciatura plena como até então ocorria e como estabelece o art. 62 da LDB.

Vivemos, portanto, ao contrário do que prega o discurso oficial, um processo de "desprofissionalização" do magistério. Finalmente, após longos cinco anos de solicitações e resistências, o próprio CNE colocou em sua pauta de discussões a discussão da Resolução no 02/97, que permite aos graduados de qualquer área se licenciarem professores, mediante uma complementação pedagógica de 5:40 horas, das quais 300 horas como estágio. Espera-se, com isso, que também seja revisto e revogado o item IV da Resolução, que cria os institutos superiores de educação e que estabelece como um de seus objetivos realizar "programas especiais de formação pedagógica, destinados a portadores de diploma de nivel superior que desejem ensinar nos anos finais no ensino fundamental ou no ensino médio, em áreas de conhecimento ou disciplinas de sua especialidade, nos termos da Resolução CNE no 02/97".

A formação continuada é uma das dimensões importantes para a materialização de uma política global para o profissional da educação, articulada à formação inicial e a condições de trabalho, salário e carreira, e deve ser entendida como 
continuidade da formação profissional, proporcionando novas reflexões sobre a ação profissional e novos meios para desenvolver e aprimorar o trabalho pedagógico; um processo de construção permanente do conhecimento e desenvolvimento profissional, a partir da formação inicial e vista como uma proposta mais ampla, de hominização, na qual o homem integral, omnilateral, produzindo-se a si mesmo, também se produz em interação com o coletivo. (ANFOPE, 1998).

Defendida pelos educadores como dever do Estado e das instituições contratantes - públicas e privadas - e direito dos professores, nas políticas educacionais atuais tal formação tem essa relação invertida. No quadro da responsabilização individual pelo aprimoramento da formação, esta deixa de fazer parte de uma política de valorização do magistério para ser entendida como um direito do Estado e um dever dos professores (Freitas, 1999).

A discussão da formação remete-nos ainda à temática das novas tecnologias e da educação a distância, estreitamente relacionada à política de formação continuada e da formação em serviço nas políticas atuais, que vem expandindo-se em ritmo acelerado por todo o país - seja por intermédio da UNIREDE, Universidade Eletrônica, Universidade Virtual ou outras formas. A gravidade da situação da formação, em particular o grande número de professores leigos, tem levado as Secretarias de Educação estaduais a estabelecer convênios com universidades para formar, a distância, os professores leigos, via TV ou outros programas, em detrimento do reforço às IES públicas para a expansão qualificada do ensino superior. Esses programas, via de regra, priorizam as tutorias em ações fragmentadas e sem vinculação com os projetos pedagógicos das escolas, bem como as formas interativas em detrimento da forma presencial, do diálogo e da construção coletiva (ANFOPE, 2000).

Esta visão tutorial e paternalista do trabalho de formação com professores, enfatizada no programa de formação continuada da Secretaria de Ensino Fundamental do MEC - Parâmetros em Ação e a Rede de Formadores -, desenvolvido por supervisores e/ou coordenadores pedagógicos e centralizado na própria escola e nos sistemas de ensino, retoma a idéia já superada na década de 1970, dos "multiplicadores", professores que passavam por processos de formação e se transformavam em formadores de professores, e assim sucessivamente, em uma "cadeia” de formação. A concepção de formação no próprio local de trabalho, se traz em si elementos inovadores ao tomar o trabalho concreto como categoria de análise, 
contraditoriamente provoca o reducionismo nas análises mais amplas e críticas desse trabalho em suas relações com a sociedade.

\section{II - As diretrizes para os cursos de formação de professores}

Como já afirmamos anteriormente, o processo de elaboração das Diretrizes Curriculares para os cursos de graduação, desencadeado pelo MEC e pelo CNE a partir de 1997, visa a adequar a formação de profissionais ao atendimento das demandas de um mercado globalizado. Considerando-se os objetivos postos pelas reformas da educação básica no sentido de adequar a formação das novas gerações às exigências postas pelas transformações no mundo do trabalho, o conteúdo e a organização das instituições de formação de professores passam a ter sua centralidade para garantir o desenvolvimento da educação básica tal como está postulada.

A necessidade de regulação originária das mudanças ocorridas no âmbito das sociedades capitalistas, no campo da formação de professores - sujeitos depositários da formação das novas gerações -, adquire caráter central, devendo responder a questóes como quais os conhecimentos necessários a todas as crianças e jovens, como desenvolver a aprendizagem desses conhecimentos, como preparar os professores (competências necessárias) para essa tarefa, quais as instituições mais adequadas e, por último, como avaliá-los nessas tarefas educativas.

Desde a deliberação que criou os institutos superiores de educação até o documento final das Diretrizes Nacionais para Formação Inicial de Professores para a Educação Básica em Nível Superior, aprovado pelo CNE em $8 / 5 / 2001^{5}$ e homologado pelo ministro da Educação em fevereiro de 2002, assistimos a iniciativas no sentido de regulação da profissão docente, sendo estes dois documentos a forma material, a expressão objetiva desse "novo" perfil que se desenha para a formação de professores para a educação básica. Seu conteúdo aborda desde as competências e habilidades a serem desenvolvidas nos futuros professores, carga horária, passando pela questão da avaliação - de curso e dos professores - até a organização institucional e pedagógica das instituições formadoras.

\section{Regulação e fragmentação do trabalho pedagógico}

No que diz respeito ao processo de construção, as diretrizes expressam as contradições presentes nas discussóes atuais, trazendo 
à tona os dilemas e as dicotomias no processo de formação: professor versus generalista, professor versus especialista e especialista versus generalista. O encaminhamento dado pelo MEC reforçou essas dicotomias, constituindo em primeiro lugar as comissões encarregadas da elaboração das diretrizes dos distintos bacharelados e somente ao seu término constituiu comissão, no âmbito do próprio MEC, para elaborar as diretrizes para a formação de professores. ${ }^{6}$

Apesar de toda a pressão das entidades e dos fóruns da área para que o processo de produção das diretrizes se desenvolvesse de forma ampla, articulada e democrática, as regulamentações anteriores no campo da formação - Resolução no 02/97, Parecer no 115/99, Decreto no 3.276/99 - acabaram determinando o conteúdo e a forma da proposta, restritos ao MEC e ao CNE. O documento final ao mesmo tempo em que incorpora reivindicações históricas do movimento, como a necessidade de um curso próprio, acaba por limitar as possibilidades de ação das instituições ao reduzir, por pressão do setor privado, a carga horária prevista no documento original de 3.200 horas para 2.800 horas a serem cumpridas no mínimo de três anos. ${ }^{7}$

Da leitura das determinações postas para a organização institucional e curricular, as competências e habilidades a serem desenvolvidas, confirmou-se a hipótese de que a decisão da SESU-MEC de formular diretrizes exclusivamente para formação de professores, ${ }^{8}$ separadas do processo de elaboração das diretrizes para o curso de pedagogia e para os bacharelados das demais áreas, visava a retirar o debate sobre formação de professores do campo maior da formação dos profissionais da educação, incluindo aí as diretrizes para o curso de pedagogia.

É nítido o fortalecimento, nessa determinação legal, dos institutos superiores de educação e do curso normal superior como espaços quase exclusivos de formação de professores. Em documento enviado ao CNE por ocasião da audiência pública para apresentação das diretrizes, a ANFOPE alerta, no que diz respeito à questão específica do locus de formação, para o forte viés, presente no documento em análise, de institucionalizar a formação de professores nos institutos superiores de educação como local exclusivo para tal missão, em vez de indicar fortemente a responsabilidade da instituição universitária como locus preferencial para o enfrentamento de tal tarefa. A retirada da formação de professores da ambiência universitária, a não-obrigatoriedade da pesquisa, o rebaixamento das exigências em relação à autorização de centros universitários e universidades, aliados à separação dessas instituições dos cursos de 
bacharelado e, portanto, da produção de conhecimento nas áreas específicas, são fatores que vêm reforçando e confirmando a formação aligeirada em seu conteúdo e no tempo destinado à formação.

No que diz respeito à retirada da formação de professores dos cursos de pedagogia, o documento das diretrizes é claro quando omite o reconhecimento desse espaço como locus de formação historicamente construído. A oposição e a resistência dos educadores à concepção fragmentada da formação - dos professores e dos "especialistas" da educação - fundam-se nos seguintes princípios:

1. Os cursos de pedagogia constituíram-se na trajetória dos últimos dez anos, como um curso de graduação plena que é licenciatura e bacharelado, com projeto pedagógico próprio, responsável pela formação de profissionais da educação, professores e "especialistas" para a educação básica, comprometidos com a educação crítica com bases sólidas, voltada para a formação humana omnilateral, emancipadora;

2. Na trajetória dos cursos de pedagogia nos últimos dez anos, a formação de professores passou a constituir o núcleo comum obrigatório do curso - nem modalidade nem habilitação - em várias IES, no entendimento de que a docência, o trabalho pedagógico constitui-se a base da formação de todos os profissionais da educação;

3. Superou-se, portanto, o entendimento da docência como habilitação, entendendo-a como fundante, base da formação do especialista, na compreensão do trabalho pedagógico escolar como totalidade que pode e deve ser apreendida no processo de formação, independente das determinações existentes no exercício profissional;

4. Esta concepção foi incorporada no documento das diretrizes curriculares para o curso de pedagogia, construídas em amplo processo de discussão, que estabelecem que a docência é a base da formação do pedagogo, respondendo ao desenvolvimento dos estudos teóricos e das práticas das instituições de ensino superior e escolares nos últimos dez anos, no entendimento de que não é possível separar teoria e prática, pensar e fazer, conteúdo e forma, no processo de formação profissional. ${ }^{9}$ 


\section{As competências como política de formação e instrumento de avaliação}

A temática das competências e sua incorporação às políticas educativas têm sido tratadas com bastante propriedade por vários estudiosos (Machado, 1998; Ramos, 2001; Manfredi, 1998; Dias, 2001; Macedo, 2000). Este modelo, incorporado acriticamente pela área educacional ou recontextualizado, na concepção de Dias (2001), com base nas reformas educativas em curso nos diferentes países, (re)aproxima a área da educação e da formação de professores do trabalho material, relação abandonada pela produção teórica na área educacional na década de 1990; realiza esta aproximação, no entanto, do ponto de vista perverso do capital. A primeira medida de política nessa direção se dá com a Parecer $n^{\circ} 115 / 99$ do CNE que regulamenta os institutos superiores de educação, instituições de caráter técnico-profissional, fato que nos permite identificar a adoção da pedagogia das competências como a "pedagogia oficial”, uma vez que ela se materializa entre nós não a partir dos avanços teóricos e práticos no campo da pedagogia e da educação, mas a partir das exigências dos organismos oficiais promotores da reforma educativa nos diferentes países visando à adequação da educação e da escola às transformações no âmbito do trabalho produtivo.

Neste estudo, ainda inicial, levanto algumas questôes no sentido de identificar pontos que merecem maior aprofundamento, com o objetivo contribuir para o desvelamento dos sentidos que este conceito adquire nas práticas do trabalho concreto de professores na escola pública.

O parecer que embasa o documento das diretrizes de formação considera "a concepção de competência (...) nuclear na organização dos cursos de formação de professores” (CNE, 2001, p. 28). Levando em conta as considerações anteriores, a respeito da incorporação desta noção e do modelo de competências na definição do perfil do novo profissional para fazer face às exigências postas pela reforma educativa, é importante destacar que esta diretriz está dada por orientaçóes firmadas anteriormente no âmbito da comissão do MEC responsável pela elaboração do documento norteador das presentes diretrizes. ${ }^{10}$ Grande parte das elaborações teóricas, entretanto, já fazia parte de documento de Mello (1999) e que mereceu nossa análise em artigo anterior (Freitas, 1999), no qual 
identificamos indícios da estreita vinculação entre as propostas para a formação de professores e as exigências postas pela reforma educativa da educação básica e pelos sistemas de avaliação em desenvolvimento. Na formulação de Mello (1999) encontramos os fundamentos que deram origem às propostas de formação contempladas pelas diretrizes:

Os professores não são necessários para qualquer projeto pedagógico, mas para aqueles que vão trabalhar de acordo com as diretrizes estabelecidas na lei, promovendo a constituição das competências definidas nas diferentes instâncias de normatização e recomendação legal e pedagógica, para ensinar e fazer aprender os conteúdos que melhor podem ancorar a constituição dessas competências. Os modelos de instituições de formação docente que interessam ao país são, portanto, aqueles que propiciam ou facilitam a construção de um perfil de profissional adequado para essa tarefa. (Mello, 1999, p. 10; grifos meus)

Outro aspecto que merece destaque é a ênfase na individualização e responsabilização dos professores pela própria formação e pelo aprimoramento profissional. Caberá aos professores "identificar melhor as suas necessidades de formação e empreender o esforço necessário para realizar sua parcela de investimento no próprio desenvolvimento profissional”.

A responsabilização individual dos professores pela aquisição de competências e pelo desenvolvimento profissional acompanha esta concepção que orienta as diretrizes e traz em conseqüência um afastamento dos professores de suas categorias, de suas organizações, tal como nos explica Isambert-Jamati:

A posse simultânea dessa série de competências, se não é a única, o que ocorre seguidamente em um número acentuado de indivíduos, é tratada, no entanto, como uma característica individual; conseqüentemente, ela não abre em si nenhuma solidariedade, já que, presumidamente, não pertence como fonte a uma categoria formalizada que, como tal, pode reivindicar direitos para todos os seus membros. (Isambert-Jamati, 1997, p. 107)

Antes pertencentes a uma categoria profissional, possuidores de uma qualificação pela qual lhes eram atribuídas determinadas tarefas e funçôes no desempenho do trabalho, ao qual era atribuído um valor pelo salário/remuneração, os trabalhadores e agora os professores se defrontam com uma nova realidade: a de disputar individualmente pela formação e competir com seus pares pelos 
espaços e tempos dos direitos anteriormente garantidos pelo conteúdo da formação profissional.

As competências, caracterizadas como um conjunto de habilidades características de cada indivíduo, contrapóem-se, neste sentido, à dimensão conceitual de qualificação profissional avaliada pelo diploma e que dá força ao conceito de profissão (Ramos, 2001).

A competência passa a estar no princípio da organização do trabalho, no lugar da qualificação/profissão. Enquanto o domínio de uma profissão, uma vez adquirido, não pode ser questionado (no máximo pode ser desenvolvido), as competências são apresentadas como propriedades instáveis dentro e fora do exercício do trabalho. Significa dizer que uma gestão fundada na competência encerra a idéia de que um assalariado deve se submeter a uma validação permanente, dando constantemente provas de sua adequação ao posto, de seu direito a uma promoção ou a uma mobilidade promocional. (Idem, p. 194)

Neste sentido, ao tomarmos como referência os estudos atuais que analisam o uso do modelo de competências nas políticas educacionais, podemos identificar que as competências listadas no documento das Diretrizes (CNE, 2002, p. 3) deslocam a discussão dos conteúdos e métodos das disciplinas que caracterizam atualmente a formação no campo da educação, não para ampliá-la para uma concepção de currículo como espaço de produção de novos conhecimentos e possibilidade de formação multilateral dos educadores, mas para reduzi-la (a formação) a um processo de desenvolvimento de competências para lidar com as técnicas e os instrumentais do ensino (tecnologia) e da ciência aplicada no campo do ensino e da aprendizagem, incluindo a visão instrumental da investigação e da pesquisa - competências referentes ao conhecimento de processos de investigação que possibilitem o aperfeiçoamento da prática pedagógica - e a individualização do processo de formação continuada competência referente ao gerenciamento do próprio desenvolvimento profissional" (idem, ibid.; grifos nossos).

Assim, ao tomar a noção de competências juntamente com o conceito de simetria invertida como nucleares nos processos de formação (CNE, 2001), o documento ajuda-nos a entender como o modelo de competências passa a ser incorporado, via formação de professores, à educação das novas gerações de modo que se as possa inserir, desde a mais tenra idade, na lógica da competitividade, da 
adaptação individual aos processos sociais e ao desenvolvimento de suas competências para a empregabilidade ou laborabilidade.

Embora não possamos transpor mecanicamente as análises sobre o modelo de competências do mundo do trabalho produtivo para o trabalho docente, a relação entre estas duas concepções competência e simetria invertida - é que dá sentido à afirmação da "necessidade de que o futuro professor experiencie, como aluno, durante todo o processo de formação, atitudes, modelos didáticos, capacidades e modos de organização que se pretende venham a ser concretizados nas suas práticas pedagógicas" (CNE, 2001, p. 17).

É este processo de regulação do trabalho, de habilidades, atitudes modelos didáticos e capacidades dos professores que permite afirmar a intenção claramente manifesta no documento de adequar a formação dos professores aos objetivos de formação postos para as crianças e os jovens na educação básica, conformando as subjetividades às novas exigências sociais.

\section{A certificação de competências e a avaliação dos professores}

A temática da profissionalização do magistério e da formação docente aproxima-se, portanto, de forma bastante estreita, da temática da avaliação. Neste aspecto particular, pela noção de competências, incorporada ao discurso oficial das novas políticas educacionais.

O currículo baseado em competências tem sido proposto, nos diferentes países, associado à idéia de avaliação. Tanto no Brasil quanto em países como a França (Tanguy, apud Ropé \& Tanguy, 1997), a definição de currículos nacionais (tais como os PCNs) e diretrizes nacionais, em termos das competências, tem se complementado com o estabelecimento de sistemas de avaliação. Desse modo, o currículo por competências passa a ser uma necessidade, já que exige a definição de desempenhos que demonstrem a sua aquisição e que possam, portanto, ser avaliados.

Como pudemos analisar, no documento das Diretrizes está clara a vinculação entre as competências a serem construídas pelos professores em formação (de acordo com essas Diretrizes) e as formas de avaliação, em um primeiro momento, dos cursos. São elas, as competências, a referência para toda e qualquer forma de avaliação: periódicas e sistemáticas, por procedimentos internos e externos e incidentes sobre processos e resultados (CNE, 2002, p. 4.). 
A primeira questão relevante a ser apontada na análise das relações entre a formação do educador e os processos de avaliação é a centralizaçãao da avaliação no âmbito do Ministério da Educação e no INEP. Não é nova a idéia de criar, nos moldes das agências que têm sido instituídas no âmbito da administração pública como órgãos de Estado, não de governo, uma Agência Nacional de Avaliação, sob comando do MEC e/ou do INEP - Instituto Nacional de Estudos e Pesquisas Educacionais.

Esta é uma idéia que está posta pelas políticas públicas em vários países, e tem suas origens nas orientaçôes do Banco Mundial visando à implementação da reforma educativa (Torres, 1996). Uma Agência Nacional de Avaliação teria como objetivo centralizar todos os processos de avaliação em todos os níveis de ensino, desde a avaliação dos conteúdos do ensino até a avaliação de docentes - de todos os professores - da educação básica à superior. ${ }^{11}$ Esta discussão da avaliação não se reduz, portanto, exclusivamente à avaliação institucional do aparato escolar, mas amplia-se para a avaliação dos sujeitos envolvidos no processo educativo - os alunos, os estudantes e os professores.

Uma primeira dimensão importante de ser destacada em relação à avaliação das competências é a dimensão da "certificação". Nessa direção, o documento introduz modificações importantes na maneira de conceber a formação e a profissionalização do magistério, entre as quais se destaca a proposta de organização de um sistema federativo de certificação de competência dos professores de educação básica. Este trabalho será coordenado e articulado pelo Ministério da Educação, em regime de colaboração com o Conselho Nacional de Educação, o Conselho Nacional de Secretários Estaduais de Educação, o Fórum Nacional de Conselhos Estaduais de Educação, a União dos Dirigentes Municipais de Educação e representantes de Conselhos Municipais de Educação e das associaçóes profissionais e científicas.

Esta iniciativa vai na direção de atender às necessidades postas pelo modelo de competências de submeter os trabalhadores/professores a uma validação permanente, como nos diz Ramos (2001), dando constantemente provas de sua adequação às necessidades do trabalho pedagógico.

Nas atuais condições do exercício do magistério, o processo de certificação de competências contribuirá para aprofundar o quadro perverso caracterizado pela ausência de políticas de valorização e de formação continuada, pelas péssimas condiçôes de funcionamento da 
grande maioria das escolas públicas e pela redução dos recursos públicos para o aprimoramento do processo educativo, trazendo como conseqüência a culpabilização e responsabilização dos professores pelo sucesso e/ou fracasso da escola e da educação pública (Codo, 1999; CNTE, 2001).

Outra dimensão da competência como instrumento de avaliação está dada pelas relações que se estabelecem entre a avaliação dos processos educativos escolares - avaliação de desempenho dos estudantes - e a avaliação do trabalho dos professores. A cada ano, quando da divulgação dos resultados de SAEB, ENEM e Provão, vemos desfilarem, pela mídia, opinióes dos mais diferentes segmentos a respeito da "qualidade" do ensino, das escolas, do processo educativo. Culpabilizam-se os professores pelo mau desempenho das crianças e dos jovens no SAEB e ENEM e responsabilizam-se as IES pelo desempenho no Provão. Nessa linha de raciocínio, desenvolvem-se, por diferentes estados brasileiros, experiências que visam a premiar os professores pelo desempenho de seus alunos no SAEB, vinculando a avaliação dos professores e provavelmente sua ascensão na carreira ao desempenho dos estudantes nos exames nacionais de avaliação escolar.

Um segundo ponto a ser destacado é a expropriação do trabalho dos professores pelas políticas avaliativas atuais. Quando a avaliação dos estudantes ao final de cada ano letivo, ou de cada ciclo, passa a ser realizada não pelos professores e pela instituição escolar, mas por uma prova nacional, que tem o poder de atribuir conceitos e decidir sobre a aprovação ou reprovação, é tempo de nos perguntarmos que profissional estas políticas pretendem construir. Esta forma de regulação do trabalho docente, embora ainda não esteja posta de maneira explícita, começou a ser introduzida no estado de São Paulo no ano de 2001. A avaliação realizada pelo SARESP - Sistema de Avaliação de Rendimento do Estado de São Paulo - não possuía, até então, caráter definidor da vida escolar de cada estudante, não tinha o poder de entrar no interior da sala de aula como forma de se contrapor à dimensão avaliativa do trabalho pedagógico, feita pelos professores sobre os seus alunos.

Os desafio que o processo de certificação de competências dos profissionais da educação nos coloca é a necessidade urgente de retomarmos a discussão presente na área educacional na década de 1980, sobre os fins da educação, e necessariamente aprofundarmos as construções históricas dos educadores no campo dos objetivos da educação, dos fins da educação e dos conteúdos da educação - os quais foram abandonados a partir da década de 1990 com as políticas neoliberais. 
A discussão que hoje está posta coloca em campos antagônicos projetos de educação e formação que privilegiam o controle do desempenho com vistas à competência e competitividade em contraposição a uma outra concepção de educação e de formação que é a formação humana omnilateral, a autonomia e o aprimoramento pessoal. Para superar este dilema no presente momento histórico, é necessário que retomemos uma categoria também abandonada pela área da educação, que é a categoria trabalho. Retomar a centralidade da categoria trabalho na discussão da formação do educador significa a possibilidade concreta de armar-se teoricamente no sentido de oposição à lógica que está posta pelas políticas neoliberais e pela política educacional atual, que é a redução do trabalho á capacidade de empregabilidade ou laborabilidade, uma "nova" competência geral propugnada pelas diretrizes oficiais a ser desenvolvida no ensino médio profissional e que se traduz pela mobilidade entre múltiplas atividades produtivas, imprescindivel numa sociedade cada vez mais complexa e dinâmica em suas descobertas e transformaçôes (CNE, 2001; grifos nossos).

Uma outra relação que se estabelece entre as políticas de formação do educador e a avaliação diz respeito à questão do financiamento das escolas e da remuneração dos professores.

Experiências desenvolvidas em alguns estados são o prenúncio do fortalecimento de uma concepção de distribuição de recursos públicos de forma "focalizada" ou "qualificada", vinculada aos resultados da avaliação do SAEB. Quando esta política se expande para os sistemas estaduais de ensino, atingindo o chão da escola, a avaliação acaba adquirindo o caráter punitivo, uma vez que vincula maior financiamento aos resultados considerados "positivos" da avaliação de seus estudantes. No Estado de São Paulo, por exemplo, as escolas estaduais vêm recebendo recursos vinculados ao desempenho das suas crianças no SARESP, recursos que variam de $\mathrm{R} \$ 2$ mil até $\mathrm{R} \$ 10$ mil. A perversidade deste modelo em sua própria lógica está visível, pois retira de escolas com menor desempenho a possibilidade de receberem maiores recursos visando a superar suas dificuldades, acentuando as diferenças, aprofundando a discriminação e desarticulando a organização dos professores nos locais de trabalho.

Por outro lado, em Fortaleza (CE), ${ }^{12}$ no ano de 2000, houve um processo de avaliação de aproximadamente 50 mil crianças com 14 e 15 anos que estavam "defasadas" na $4^{a}$ série do ensino fundamental. Os resultados da avaliação dos alunos permitiram que cada professor pudesse receber um valor adicional de $\mathrm{R} \$ 40$ por aluno 
que tivesse obtido nota 7 em cada uma das disciplinas. Isso significou uma gratificação para os professores de até $\mathrm{R} \$ 4$ mil por conta da forma de avaliação e da vinculação do desempenho/remuneração dos professores ao desempenho de seus alunos.

Estas iniciativas vão dando pistas, indicaçôes de que os próximos passos a serem implementados pelos sistemas estaduais de ensino vão na direção de estabelecer sistemas de avaliação de seus professores estreitamente vinculados aos resultados da avaliação nacional realizada pelo SAEB e pelos sistemas estaduais, como o SARESP.

\section{Conclusões}

As orientações gerais da política educacional no campo da formação obedecem, conforme nossa análise, às necessidades postas pela reforma educativa para a educação básica em decorrência das transformações no campo produtivo e das novas configurações no desenvolvimento do capitalismo.

Para entender em profundidade as novas configurações postas pelas determinações legais para a formação de professores, é preciso que ampliemos cada vez mais as análises do trabalho docente, tomando a categoria trabalho, para entendê-la em suas relações contraditórias - como mercadoria e como realização humana produzida historicamente - e em suas articulaçôes com as transformações que ocorrem no campo do trabalho produtivo, com a reestruturação produtiva e a inserção do Brasil no processo de globalização e competitividade internacional.

Esta aproximação nos permite vislumbrar e identificar qual será, do ponto de vista do capital, o professor e o "pedagogo" necessários no processo de transformação por que passa a educação básica e a escola, em decorrência das reformas educativas. É preciso que apuremos nosso olhar para encontrar aí as semelhanças e diferenças com os paradigmas do tecnicismo da década de 1970, que agora retorna com mais vigor e com as novas exigências postas para a formação dos trabalhadores, incluídos aí os professores, ainda que não seja adequada uma transposição mecânica da análise relativa às mudanças no mundo do trabalho produtivo para o campo da educação e da escola.

A hipótese com a qual vimos trabalhando (Freitas, 1999) infelizmente vai se confirmando. A necessidade de expansão da escolarização, a impossibilidade de o Estado - em seu novo papel 
de Estado mínimo - prover os recursos necessários que garantam a expansão da educação superior pública, em particular na formação de seus professores, e, em conseqüência, a impossibilidade de garantir uma formação qualitativamente superior - universitária, nas condições atuais - para todos os professores, fundada na investigação e na pesquisa e sobre novas bases de produção do trabalho docente nas escolas públicas, têm direcionado o esforço do Poder Público no sentido de expandir o ensino superior privado como mecanismo de intensificação/massificação da formação de professores de caráter técnico-profissional, instrumental, ampliando as formas de avaliação, objetivando a regulação e o controle do trabalho dos professores na implantação do conteúdo da reforma educativa e do projeto de educação e sociedade excludente.

Estamos assim vivenciando, pelas políticas de formação, concepções que, pela desresponsabilização do Estado do financiamento público, pela individualização das responsabilidades sobre os professores, pela centralidade da noção de certificação de competências nos documentos orientadores da formação de professores, revelam um processo de flexibilização do trabalho docente em contraposição à profissionalização do magistério, condição para uma educação emancipadora das novas gerações.

Ao avaliarmos a política de formação de professores, podemos reafirmar que o aprimoramento da escola e a educação de nossas crianças, jovens e adultos se encontram comprometidos pelo desenvolvimento de diretrizes legais que privilegiam o aligeiramento e o rebaixamento da formação com cursos de menor carga horária em relação àquelas profissôes mais valorizadas socialmente; privilegiam a formação descomprometida com a pesquisa, a investigação e a formação multidisciplinar sólida ao deslocar a formação da universidade e, em seu interior, das faculdades/centros de educação e cursos de pedagogia para os institutos superiores de educação e cursos normais superiores em instituições isoladas; privilegiam processos de avaliação de desempenho e de competências vinculadas ao saber fazer e ao como fazer em vez de processos que tomam o campo da educação em sua totalidade, com seu status epistemológico próprio, retirando a formação de professores do campo da educação para o campo exclusivo da prática.

Vai se conformando, portanto, uma política de formação de professores que tem na certificação de competências e na avaliação sua centralidade. É preciso que recoloquemos em questão as constru- 
çôes históricas dos educadores na luta pela formação de qualidade e por uma política global de formação dos profissionais da educação e de valorização do magistério. Retomar as discussões sobre os fins da educação significa trazer à tona a questão dos projetos históricos e do futuro que queremos construir hoje para nosso povo, lidando com as contradiçóes próprias dos processos educativos.

Somente esta questão nos pode dar o norte seguro para pensar a formação dos profissionais professores necessários para lidar com a concepção mais avançada de preparação das novas gerações para construir uma nova vida, uma nova humanidade.

Estes últimos dez anos de políticas neoliberais nos mostraram a que vieram os diferentes governantes e governos. Deixam-nos um legado de desigualdade, concentração de renda, ${ }^{13}$ desemprego e miséria. O prenúncio de uma nova vida e uma nova humanidade somente pode ser anunciado e construído lidando com as contradições da realidade atual.

Este é o desafio que está historicamente posto para os educadores e para o nosso povo.

\section{Recebido e aprovado em julho de 2002.}

\section{Notas}

1. O Decreto no $3.276 / 99$, o qual estabelecia que a formação de professores para séries iniciais e educação infantil se faria exclusivamente em cursos normais superiores, foi uma tentativa nesse sentido. Posteriormente modificado pelo Decreto $n^{\circ} 3.554 /$ 2000, alterou o "exclusivamente" para "preferencialmente", mantendo, ainda que com reservas, o direcionamento da formação para o novo espaço dos institutos superiores de educação.

2. Com ênfase nos estudos do trabalho docente, tomando como categoria de análise o trabalho material presente nos estudos da área e nos encontros principalmente da ANPED e do ENDIPE até o final da década de 1980.

3. Dados do Censo 2000 indicam a existência de 1.180 instituições credenciadas em nosso país, sendo 1.004 particulares e apenas 176 públicas, ou seja, 85\% do total. Em 1996 esta relação era de $23 \%$ para as instituições públicas e $77 \%$ para as privadas, sendo que na década de 1970 esta proporção era de $70 \%$ para as públicas e $30 \%$ para as privadas! Cf. Censo 2000 e Marques \& Pereira, 2002.

4. Mais detalhes sobre o Programa Parâmetros em Ação, ver site da ANFOPE: http:// lite.fae.unicamp.br/anfope e site do próprio MEC: www.mec.gov.br.

5. Posteriormente os Pareceres no 21/017, no 27/2001 e no 28/2001 alteraram dispositivos que estabeleciam a carga horária dos cursos de licenciatura relativa aos componentes curriculares e às práticas de ensino, estágios e outras atividades. 
6. Importante registrar que as diretrizes para o curso de pedagogia, elaboradas em amplo processo de discussão com a área e finalizadas em maio de 1999, não foram até o momento aprovadas pelo CNE.

7. Importante destacar que a redução da carga horária se estendeu a praticamente todas as diretrizes curriculares de graduação, com exceções nas áreas "nobres" como medicina e engenharias. $\mathrm{Na}$ área do direito a pressão da OAB sobre o Ministério da Educação fez com que o ministro voltasse atrás na intenção de reduzir o curso para três anos e 2.800 horas.

8. Cf. Boletim ANFOPE no 11 , de agosto de 1999.

9. Cf. Anfope, Carta aos Conselheiros do CNE, de agosto de 1999; cf. ainda documento das entidades enviado ao CNE em 2001, Posicionamento conjunto das entidades ANPED, ANFOPE, anPae, forumdir e Fórum Nacional em Defesa da Formação do Professor.

10. Comissão composta por Ruy Leite Berger Filho (Coordenação-Geral) - SEMTEC; Célia Maria Carolino Pires - SEF; Guiomar Namo de Mello (coordenadora) - SEMTEC; Maria Beatriz Gomes da Silva - SEMTEC; Maria Inês Laranjeira - SESU; Neide Marisa Rodrigues Nogueira - SEF; e Rubens de Oliveira Martins - SESU.

11. Recentemente as atribuições de autorização e o reconhecimento de curso, antes localizadas no MEC, foram transferidos para o INEP, que vem desenvolvendo um grande projeto de incorporar ao seu quadro de "avaliadores" cerca de 10 mil professores universitários de diferentes áreas e diferentes IES. Este corpo de avaliadores será responsável pelos processos de autorização, credenciamento e recredenciamento de cursos, bem como pelas avaliações das condiçōes do ensino de graduação (ex-avaliação das condições de oferta) do Exame Nacional de Cursos - Provão.

12. Informação fornecida pelo secretário de Educação do Ceará e conselheiro, professor Naspolini, durante seminário sobre avaliação dos docentes, realizado pelo CNE em setembro de 2000, em Brasília.

13. Cf. o Relatório sobre o desenvolvimento humano, 2002, da onU, que aponta o aumento da concentração de renda no Braisl como uma das quatro maiores do mundo.

\section{Referências Bibliográficas}

AGUIAR, M.A. Institutos Superiores de Educação na nova LDB. In: BRZEZINSKI, Iria (Org.), LDB interpretada: diversos olhares se entrecruzam. São Paulo: Cortez, 1997.

AGUIAR, M.A. A formação do profissional da educação no contexto da reforma educacional brasileira. In: FerReIRA, N.S.C. (Org.). Supervisão educacional para uma escola de qualidade. São Paulo: Cortez, 1999.

ANPED, ANFope, ANPAE, FORUMdir e Fórum Nacional em Defesa da Formação do Professor. Documento apresentado na Reunião de Consulta com o Setor Acadêmico no âmbito do Programa Especial "Mobilização Nacional por uma Nova Educação Básica”. Brasília: CNE, 7/11/2001.

Educ. Soc., Campinas, v. 23, n. 80, setembro/2002, p. 136-167 
ASSOCIAÇÃO NACIONAL PELA FORMAÇÃO DE PROFISSIONAIS DA EDUCAÇÃO. Contribuições para subsidiar discussão na audiência pública nacional do CNE sobre a Proposta de Diretrizes Nacionais para Formação Inicial de Professores para a Educação Básica em cursos de nível superior. Brasília, DF: ANFOPE, 2001.

BRASIL. Lei de Diretrizes e Bases da Educação Nacional. Lei no 9.394, de 20 de dezembro de 1996. Estabelece as diretrizes e bases da educação nacional. Diário Oficial da União, Brasília, DF, 23 dez. 1996.

CANDAU, V. M.; LÜDKE, M. Novos rumos da licenciatura. Brasília: MEC/INEP, 1988. (pesquisa)

CATANI, A.M.; OLIVEIRA, J.F.; DOURADO, L.F. Mudanças no mundo do trabalho e reforma curricular dos cursos de graduação no Brasil. In: REUNIĀO ANUAL DA ANPED, 23., 2000, Caxambu. Anais... Caxambu, 2000..

CODO, W. (Coord.). Educação: carinho e trabalho. Rio de Janeiro: Vozes, 1999.

COMISSÃO DE ESPECIALISTAS DE ENSINO DE PEDAGOGIA. Diretrizes curriculares para o curso de pedagogia. Brasília, DF: MEC/ SESU, 1999.

COMITÊ PRÓ-REFORMULAÇÃO DOS CURSOS DE FORMAÇÃO DO EDUCADOR. Documento do I encontro. Belo Horizonte, 1983.

CONFEDERAÇÃO NACIONAL DOS TRABALHADORES EM EDUCAÇĀAO. Retrato da escola. Brasília, DF: CNTE, 1999. Disponível em: <www.cnte.org.br> Acesso em: 2002.

CONFEDERAÇÃO NACIONAL DOS TRABALHADORES EM EDUCAÇÂO. Retrato da escola II. Brasília, DF: CNTE, 2001. Disponível em: <www.cnte.org.br> Acesso em: 2002.

CONSELHO NACIONAL DE EDUCAÇÃO. Mobilização nacional por uma nova educação básica. Brasília, DF: CNE, 2001. (Documento-síntese)

DIAS, R.E. Competências: um conceito recontextualizado no currículo para formação de professores no Brasil. In: REUNIÃO ANUAL DA ANPED, 23., 2000, Caxambu. Anais... Caxambu, 2000. 
ENCONTRO NACIONAL DA ANFOPE, 6., 1992, Belo Horizonte. Documento final. Belo Horizonte, 1992

ENCONTRO NACIONAL DA ANFOPE, 7., 1994, Niterói. Documento final. Niterói, 1994.

ENCONTRO NACIONAL DA ANFOPE, 8., 1996, Belo Horizonte. Documento final. Belo Horizonte, 1996.

ENCONTRO NACIONAL DA ANFOPE, 9., 1998, Campinas. Documento final. Campinas, 1998.

ENCONTRO NACIONAL DA ANFOPE, 10., 2000, Brasília. Documento final. Brasília, 2000.

ENCONTRO NACIONAL DA CONARCFE, 3., 1988, Brasília. Documento final. Brasília, DF, 1988.

ENCONTRO NACIONAL DA CONARCFE, 4., 1989, Belo Horizonte. Documento final. Belo Horizonte, 1989.

ENCONTRO NACIONAL DA CONARCFE, 5., 1990, Belo Horizonte. Documento final. Belo Horizonte, 1990.

FRANCO, M.A.S. Indicativos para um currículo de formação de pedagogos. In: ENDIPE, 11., 2002, Goiânia. Anais... Goiânia, 2002.

FREITAS, H.C.L. Plano Decenal de Educação: consenso e cooptação. Revista do SINPEEM, São Paulo, n. 2, fev. 1995.

FREITAS, H.C.L. Trabalho como principio articulador nos estágios supervisionados. Campinas: Papirus, 1996.

FREITAS, H.C.L. A reforma universitária no campo da formação dos profissionais da educação básica: as políticas educacionais e o movimento dos educadores. Educ. Soc., Campinas, v. 20, n. 68, dez. 1999.

FREITAS, L.C. Em direção a uma política para a formação de professores. Em Aberto, Brasília, DF, v. 12, n. 54, abr./jun. 1992.

FREITAS, L.C. Neotecnicismo e formação do educador. In: Alves, Nilda (Org.). Formação de professores, pensar e fazer. São Paulo: Cortez, 1992.

FREITAS, L.C. Ensino de $1^{\circ}$ grau: instrumento de recuperação econômica? Universidade e Sociedade, São Paulo, v. 4, n. 7, jun. 1994. 
FREITAS, L.C. Palestra de abertura do II Encontro da Regional Sul da ANFOPE. Florianópolis, 1998. (mimeo.).

FREITAS, L.C. Cenário educacional: o legado dos anos 80 e a confusão dos anos 90. E agora? In: SIMPOSIO DO LAGE, 3., 2000, Jundiaí. Anais... Jundiaí, 2000.

FREITAS, L.C. É necessário radicalizar: curvando a vara em outra direção. Revista PucViva, São Paulo, v. 4, n. 13, p. 7-10, 2001.

ISAMBERT-JAMATI, V. O apelo à noção de competência na revista L'Òrientation Scolaire et Professionelle: da sua criação aos dias de hoje. In: Ropé, F.; TANGUY, L. (Orgs.). Saberes e competências: o uso de tais noções na escola e na empresa. Campinas: Papirus, 1997.

KUENZER, A.Z. A formação dos profissionais da educação: propostas de diretrizes curriculares nacionais. [BELO HORIZONTE]: ANPED, 1998. (mimeo.).

KUENZER, A.Z. A formação de educadores no contexto das mudanças do mundo do trabalho: novos desafios para as faculdades de educação. Educ. Soc., Campinas, v. 19, n. 63, ago. 1998.

LINHART, D. O indivíduo no centro da modernização das empresas: um reconhecimento esperado mas perigoso. Trabalho $e$ Educação - Revista do NETE, Belo Horizonte, n. 7, jul./dez. 2000 .

LÜDKE, M. Avaliação institucional: formação de professores para o ensino fundamental e médio (as licenciaturas). Brasília, DF: CRUB, 1994.

MACEDO, E. Formação de professores e diretrizes curriculares nacionais: para onde caminha a educação? In: REUNIÃO ANUAL DA ANPED, 23., 2000, Caxambu. Anais... Caxambu, 2000.

MACHADO, L.R.S. Educação básica, empregabilidade e competência. Trabalho e Educação - Revista do NETE, Belo Horizonte, n. 3, jan./jul. 1998.

MACHADO, L.R.S. O “modelo de competências" e a regulamentação da base curricular nacional e de organização do ensino médio. Trabalho e Educação - Revista do NETE, Belo Horizonte, n. 4, ago./dez. 1998. 
MANFREDI, S.M. Trabalho, qualificação e competência profissional: das dimensōes conceituais e políticas. Educ. Soc., Campinas, v. 19, n. 64, set. 1998.

MARQUES, C.A.; DINIZ, J.P. Fóruns de licenciaturas em universidades brasileiras: construindo alternativas para a formação inicial de professores. Educ. Soc., Campinas, v. 23, n. 78, abr. 2002.

MELLO, G.N. Formação inicial de professores para a educação básica: uma revisão radical. 1999. (Documento principal - versão preliminar para discussão interna. Mimeo.).

RAMOS, M.N. A pedagogia das competências: autonomia ou adaptação? São Paulo: Cortez, 2001.

TANGUY, L. Racionalização pedagógica e legitimidade política. In: Ropé, F.; TAnguY, L. (Orgs.). Saberes e competências: o uso de tais noçōes na escola e na empresa. Campinas: Papirus, 1997.

TORRES, R.M. Melhorar a qualidade da educação básica?: as estratégias do Banco Mundial. In: De TOMMASI, L., WARDE, M.J.; HADDAD, S. (Orgs.). O Banco Mundial e as politicas educacionais. São Paulo: Cortez, 1996.

VALLE, B.B.R. A nova LDB e os institutos superiores de educação: histórias do passado, presente e futuro. In: SouZA, D.B.; CARINO, J. (Orgs.). Pedagogo ou professor?: o processo de reestruturação dos cursos de educação no Rio de Janeiro. Rio de Janeiro: Quartet, 1999.

VALLE, B.B.R. Formação de professores no Brasil: perspectivas para os próximos anos. In: SouZA, D.B.; Ferreira, R. (Orgs.). Bacharel ou professor?: o processo de reestruturação dos cursos de formação de professores no Rio de Janeiro. Rio de Janeiro: Quartet, 2000.

WHITTY, G. Controle do currículo e quase-mercados: a recente reforma educacional na Inglaterra e no País de Gales. Trabalho apresentado no II Seminário Internacional "Novas Políticas Educacionais: críticas e perspectivas". São Paulo: Pontifícia Universidade Católica de São Paulo, 1996. 